\title{
Angiographically occult vascular malformation of the intracranial accessory nerve: case report
}

\author{
Sergei Terterov, MD, ${ }^{1}$ Nancy McLaughlin, MD, PhD, FRCSC, ${ }^{1}$ Harry Vinters, MD, ${ }^{2}$ and \\ Neil A. Martin, MD' \\ Departments of ${ }^{1}$ Neurosurgery and ${ }^{2}$ Pathology, David Geffen School of Medicine at UCLA, Los Angeles, California
}

\begin{abstract}
Angiographically occult cerebral vascular malformations (AOVMs) are usually found in the supratentorial brain parenchyma. Uncommonly, AOVMs can be found within the cavernous sinus or basal cisterns and can be associated with cranial nerves. AOVMs involving the intracranial segment of the spinal accessory nerve have not been described. A 46-year-old female patient presented with a history of episodic frontal headaches and episodes of nausea and dizziness, as well as gait instability progressing over 6 months prior to evaluation. Imaging revealed a well-circumscribed 3-cm extraaxial T1-weighted isointense and T2-weighted hyperintense contrast-enhancing mass centered in the region of the right lateral cerebellomedullary cistern. The patient underwent resection of the lesion. Although the intraoperative appearance was suggestive of a cavernous malformation, some histological findings were atypical, leading to the final diagnosis of vascular malformation, not otherwise specified. The patient's postoperative course was uneventful with complete resolution of symptoms. To the authors' knowledge, this is the first report of an AOVM involving the intracranial portion of the accessory nerve. For any AOVM located within the cerebellomedullary cistern or one suspected of involving a cranial nerve, the authors recommend including immunohistochemistry with primary antibody to neurofilament in the histopathology workup.
\end{abstract}

http://thejns.org/doi/abs/10.3171/2015.6.JNS131105

KEY WORDS vascular malformation; angiographically occult; cavernous malformation; cranial nerve; accessory nerve; vascular disorders

A NGIOGRAPHICALLY occult cerebral vascular malformation (AOVM) is a clinicoradiographic term that describes a heterogeneous group of entities, including cavernous malformations (CMs), thrombosed arteriovenous malformations, venous malformations, capillary telangiectasias, and mixed vascular malformations. ${ }^{48}$ These account for 5\%-15\% of all cerebral vascular lesions, with a general population prevalence estimated at $0.3 \%-0.5 \%$. Approximately half of AOVMs occur sporadically, while the other half are inherited in an autosomaldominant pattern. Given that histologically most AOVMs are CMs, the current literature concerns patient populations with CMs. Indeed, only a minority of AOVMs are venous malformations, arteriovenous malformations, or mixed vascular malformations. ${ }^{52,56} \mathrm{CMs}$ are found within the brain parenchyma in approximately $95 \%$ of cases, with spinal CMs accounting for 5\%. Of the intracranial CMs, $80 \%$ are supratentorial and $20 \%$ are infratentorial. ${ }^{33} \mathrm{CMs}$ usually have a characteristic appearance on MRI with a mixed T2 signal intensity reticulated core surrounded by a rim of decreased signal intensity. However, smaller lesions can appear as small areas of decreased signal intensity. ${ }^{24,57}$

Uncommonly, CMs (as the most common form of AOVMs) can be found within the cavernous sinus, basal cisterns, cauda equina, and cranial nerves..$^{10,41,43,44}$ Although CMs have been previously reported to be associated with almost all cranial nerves, their involvement of the lower cranial nerves is extremely rare. We report a case of an angiographically occult vascular malformation (AOVM) arising from the intracranial portion of the spinal accessory nerve, with pathological confirmation of nerve fibers traversing the lesion.

\section{Case Report}

History and Presentation

A 46-year-old woman presented with a history of episodic frontal headaches and episodes of nausea and diz-

ABBREVIATIONS AVOM = angiographically occult cerebral vascular malformation; $C M=$ cavernous malformation; $S M A=$ smooth muscle actin.

SUBMITTED May 27, 2013. ACCEPTED June 3, 2015.

INCLUDE WHEN CITING Published online November 13, 2015; DOI: 10.3171/2015.6.JNS131105. 
ziness, as well as gait instability progressing over the 6 months prior to evaluation. The patient denied difficulty with fine motor coordination, dysarthria, dysphonia, or dysphagia. Her medical history was unremarkable. Results of a detailed physical examination were completely normal at this time.

Brain MRI showed a well-circumscribed $29 \mathrm{~mm}$ (anteroposterior) $\times 23 \mathrm{~mm}$ (transverse) $\times 29 \mathrm{~mm}$ (craniocaudal) extraaxial mass centered in the region of the right lateral cerebellomedullary cistern. The mass appeared isointense on T1-weighted and hyperintense on T2weighted imaging, and enhanced heterogeneously following gadolinium injection (Fig. 1). The lesion caused distortion and compression of the lower medulla and inferior aspect of the fourth ventricle. However, there was no focal signal abnormality within the medulla and no obstructive hydrocephalus. The initial working diagnosis included ependymoma or choroid plexus papilloma. A catheter angiogram showed no arterial feeders supplying the lesion.

\section{Surgical Procedure}

The patient underwent a midline suboccipital posterior fossa craniotomy and resection of the posterior arch of C-1. Intraoperative neuromonitoring included electroencephalography, somatosensory evoked potentials, brainstem auditory evoked potentials, facial electromyography, and lower cranial nerve monitoring. After dural opening and incision of the arachnoid, a reddish-purple lesion was seen elevating the right cerebellar hemisphere (Fig. 2A). The arachnoid was separated from the surface of the well-circumscribed mass. After stimulating the capsule with the nerve stimulator, the surface was coagulated and incised. The frozen pathology section was suggestive of AOVM. Once the central portion of the mass was resected, the capsule was folded inward and the arachnoid was separated circumferentially. There was at least one rootlet of the spinal component of the spinal accessory nerve that entered the central substance of the mass at its inferolateral pole. It could not be stripped from the lesion's capsule (Fig. 2B). A component of the spinal accessory nerve was also seen exiting from the mass prior to coursing toward the jugular foramen (Fig. 2C). Again, this could not be separated from the tumor capsule. Therefore, a component of the spinal accessory nerve was included within the tumor and could not be salvaged. The medullary roots of the spinal accessory nerve, however, were well visualized and were preserved by dissecting the arachnoid away from the capsule of the tumor. The hypoglossal nerve fibers were also identified and preserved, as were the ninth and tenth cranial nerves. By dividing the involved rootlet of the spinal accessory nerve proximally and distally, the mass was freed and completely resected (Fig. 2D). The lateral brainstem and the inferior pial surface of the cerebellum were entirely intact, with no hemosiderin coloration.

\section{Histopathology Findings}

The resected lesion was examined using routine $(\mathrm{H} \&$ E) stains, Masson trichrome, and immunohistochemistry using primary antibodies to smooth muscle actin (SMA), neurofilament, and factor VIII, together with appropriate positive and negative controls. Routine stains showed a vascular lesion composed of ectatic and dilated vascular
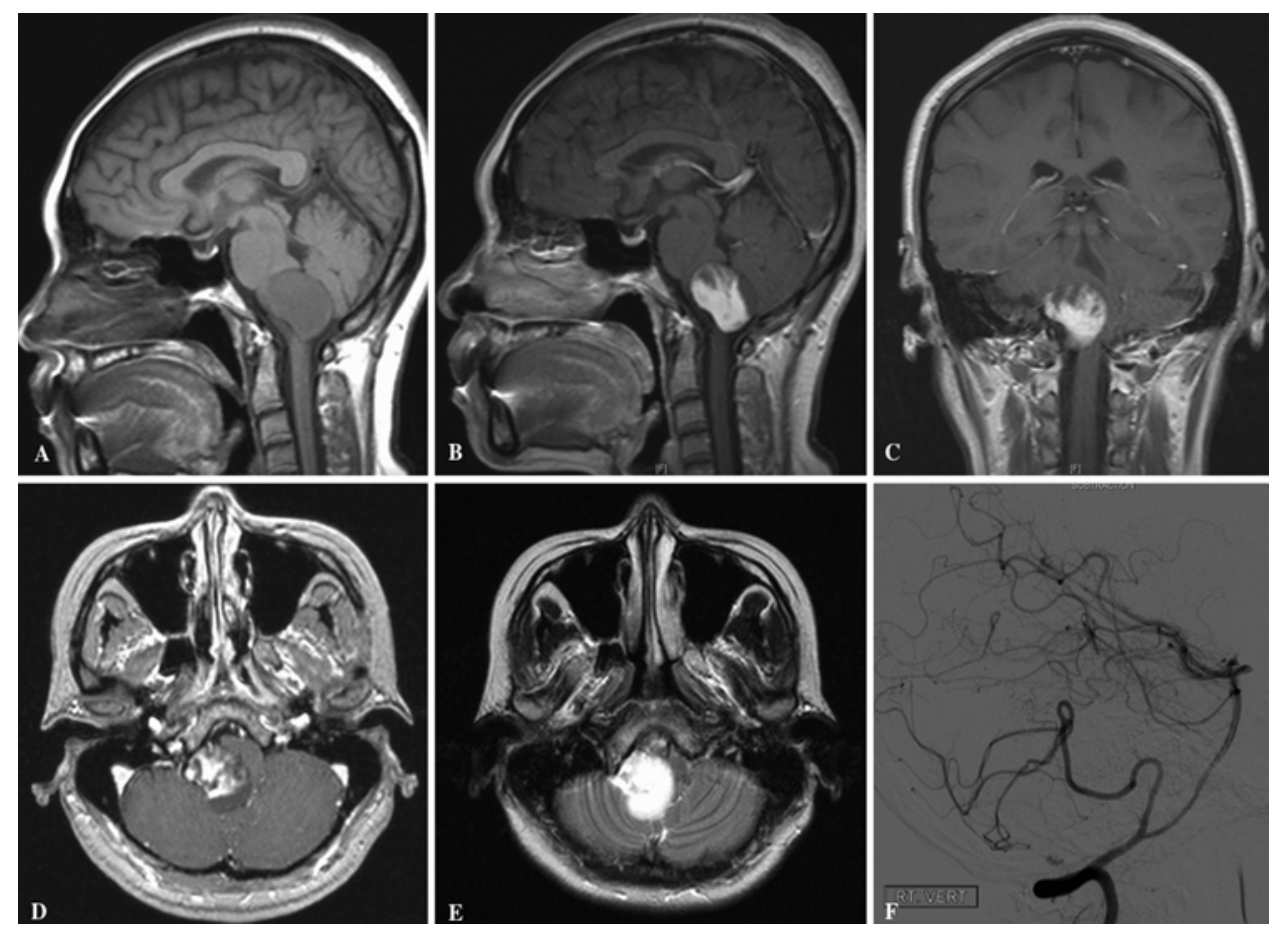

FIG. 1. Sagittal T1-weighted images without (A) and with (B) gadolinium, coronal (C) and axial (D) T1-weighted gadoliniumenhanced images, and axial T2-weighted image (E) demonstrating a partially cystic, heterogeneously enhancing lesion in the cerebellomedullary cistern exerting significant mass effect on the brainstem. Lateral angiographic projection of the right vertebral artery injection with no evidence of vascular abnormality (F). 

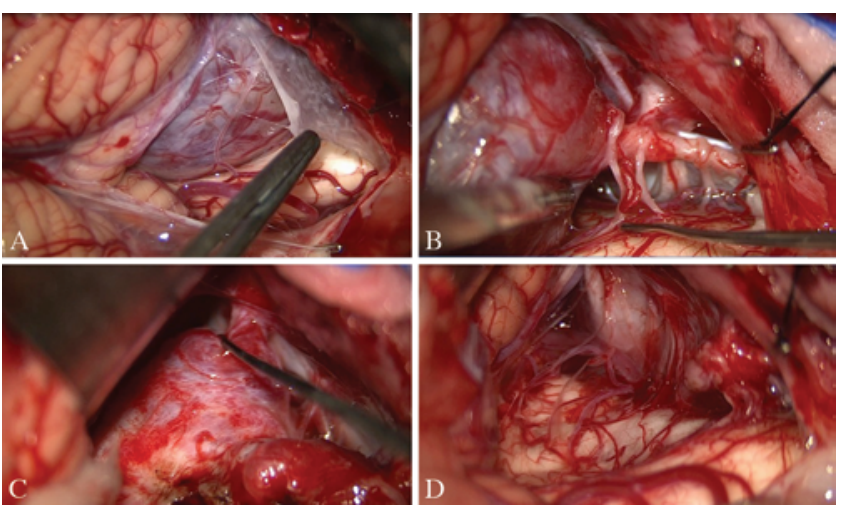

FIG. 2. Intraoperative photographs under $10 \times$ magnification. A: A reddish-purple lesion elevating the right cerebellar hemisphere. $B$ : A fiber of the spinal component of the spinal accessory nerve entering the central substance of the mass at its inferolateral pole. C: A component of the spinal accessory nerve exiting from the mass (by the dissector). D: Resection cavity after removal of the lesion. Figure is available in color online only.

channels. Walls of these vessels were markedly thickened and contained a basophilic amorphous material, within which were closely apposed spindle cells (Fig. 3A-C), most of which were strongly immunoreactive for SMA (Fig. 3D-F). Endothelium of the vascular channels was normal by both routine stains and factor VIII immunohistochemistry (not shown). Neurofilament immunohistochemistry confirmed the presence of immunoreactive nerve twigs at the edge of the lesion and occasional nerve twigs among the vascular channels themselves (Fig. 3D-F). Some of the nerve twigs showed degenerative change, including axonal "bulbs" (resembling neuroaxonal spheroids in the central nervous system) and fragmentation (Fig. 3E and F). Although histopathological findings were suggestive of a $\mathrm{CM}$, the presence of a smooth muscle component was atypical for the classic diagnosis of CM. Also, there was a relative absence of altered blood pigment (hemosiderin) in or around the lesion, as seen typically in intraparenchymal CMs. The final pathological diagnosis was that of a vascular malformation, not otherwise specified.

\section{Postoperative Course}

The patient had an uncomplicated postoperative course. On postoperative Day 1, her brain MRI study demonstrated complete resection of the cerebellomedullary cistern lesion (Fig. 4). She was seen in the clinic 1 month after surgery and noted complete resolution of her preoperative symptoms. On physical examination, no weakness or atrophy of the right sternocleidomastoid and trapezius muscles was noted. The patient was recently seen 1 year after her intervention and remains asymptomatic, with no evidence of residual lesion on follow-up MRI.

\section{Discussion}

\section{AOVMs and Cranial Nerves}

AOVMs (most frequently $\mathrm{CMs}$ ) frequently involve the brain parenchyma, but the involvement of the cavernous sinus, the basal cisterns, and various cranial nerves is well described..$^{41,43,44}$ The most common cranial nerve associat-

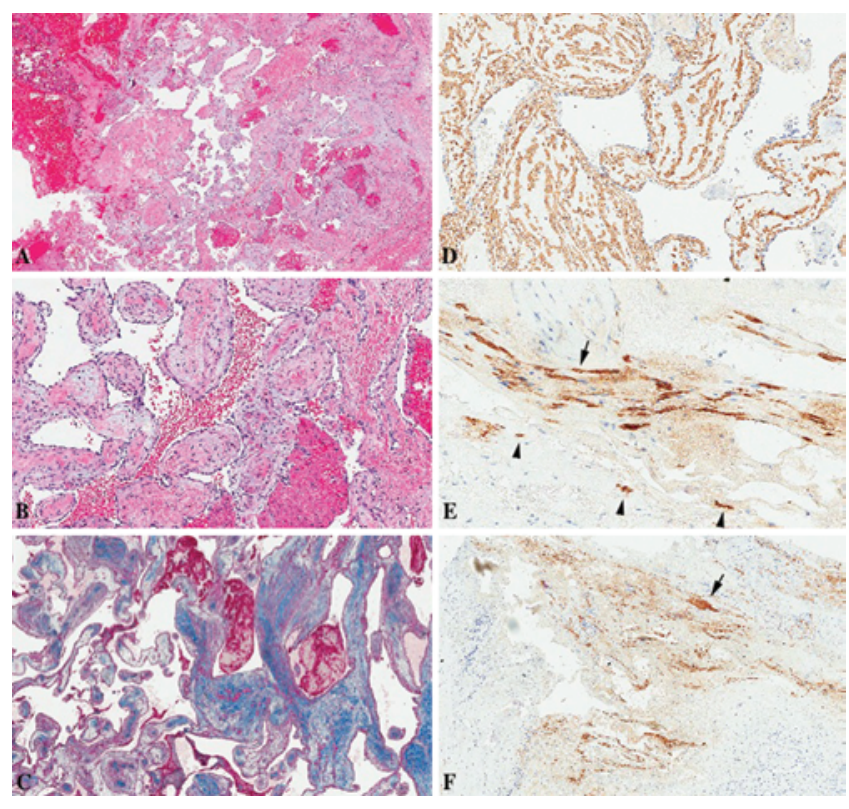

FIG. 3. A: Low-power view of the specimen showing abundant acute hemorrhage, and ectatic/dilated vascular channels separated by variably thickened vessel walls. B: Magnified view from a representative portion of the AOVM showing lumens to be lined by normal endothelium; vessel walls are composed predominantly of spindle cells in a faintly basophilic matrix. C: Masson trichrome stain highlights thickened vessel walls in the AOVM. D-F: Immunohistochemical studies. D: Section immunostained with primary antibodies to SMA showing a significant element of smooth muscle cells in the vessel walls. $E$ and F: Sections immunostained with primary antibodies to neurofilament. Arrow (in E) indicates several immunoreactive axons at the edge of the specimen, while arrowheads indicate nerve twigs among vascular channels. Many discontinuous nerve twigs are seen $(F)$; the arrow indicates a dilated and swollen axon possibly representing degenerative change. Original magnification $\times 40(A) ; \times 95(B-D$ and $F) ; \times 180(E)$. Figure is available in color online only.

ed with an AOVM is the optic nerve, with at least 18 reported cases involving the optic pathways, typically presenting with sudden visual acuity deterioration. 3,13,19-22,27,31,34,36,38,47,59 The oculomotor nerve was involved by an AOVM in 4 reported cases, most frequently presenting with ophthalmoplegia and diplopia. . $^{30,40,45,58}$ In 3 cases, the trochlear nerve was involved, presenting clinically with either progressive diplopia or hemisensory loss symptoms..$^{37,51,53}$ There are 5 reports of trigeminal nerve or ganglion AOVMs, most commonly presenting with facial dysesthesia or hypesthesias. ${ }^{11,14,17,39,47}$ Only one case of an AOVM involving the abducens nerve has been reported, which presented with recurrent episodes of diplopia. ${ }^{43}$ There are 8 reported cases of AOVMs involving the cranial nerve VII/VIII complex, with 5 described to originate from the facial nerve and 3 from the vestibular nerve. . $^{1,916,18,28,40,42}$

Approximately 40 cases of AOVMs within the internal auditory canal have been published, with no specification as to the cranial nerve origin of the lesion. ${ }^{5-7,15,46,49}$ The AOVMs in these locations most commonly present with sensorineural hearing loss, hemifacial spasm, or tinnitus. ${ }^{49}$ In addition, approximately 50 cases of cerebellopontine angle AOVMs have been reported in the literature. ${ }^{1,8,29,32}$ These lesions were not directly associated with the cranial 


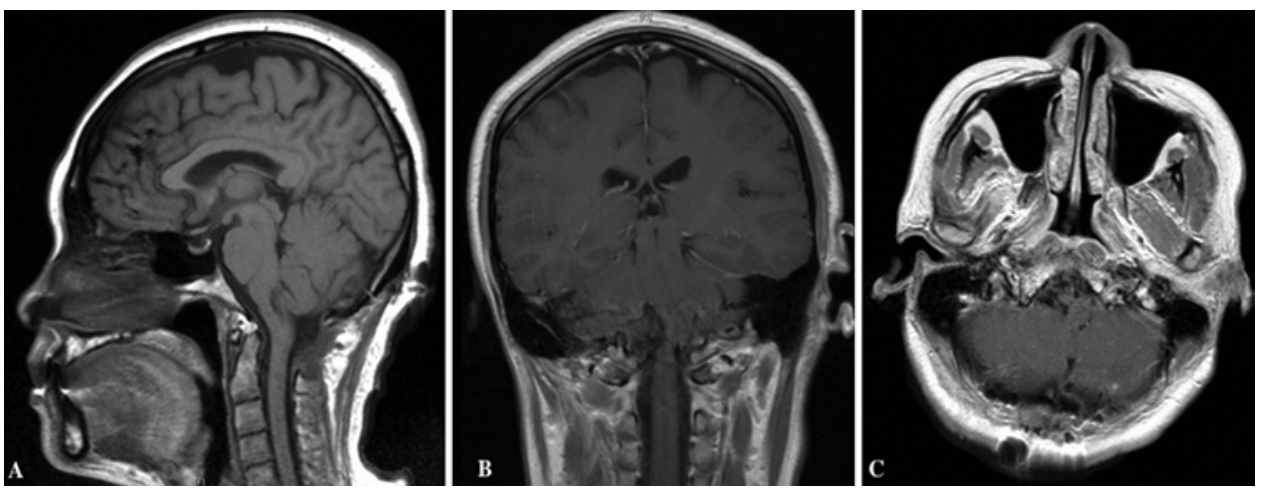

FIG. 4. Postoperative MR images. Sagittal T1-weighted (A) and gadolinium-enhanced T1-weighted coronal (B) and axial (C) images demonstrating complete excision of the lesion with no residual areas of enhancement and decompression of the brainstem.

nerves; however, they were commonly exerting mass effect on them. Only one report exists of an AOVM involving the lower cranial nerves in a patient presenting with changes in the tone of voice. ${ }^{2}$ However, it is unclear if the lesion actually originated from one of the lower cranial nerves, and if so from which one. There is one reported case of a hypoglossal nerve AOVM presenting with tongue deviation and dysarthria. ${ }^{12}$

\section{Imaging and Pathology Findings of Cranial Nerve-Associated AOVMs}

Imaging findings of AOVMs associated with cranial nerves may lack the classic reticulated appearance and resemble other benign lesions such as meningioma or schwannoma..$^{14,37,39}$ To date, although multiple reports describe the finding of neuronal tissue within the AOVM, it remains challenging to ascertain whether the AOVM is originating from within the cranial nerve and splaying the nerve fibers at its periphery, or if the AOVM has originated outside of the nerve tissue and is encompassing some of its fibers. Intermingled cavernous and neural tissue has been described only in a minority of cases of cranial nerve-associated AOVMs. ${ }^{19,17,29,32,38,40,43,53}$ Although the described case was radiographically and clinically suggestive of a CM of the accessory nerve, some histopathological features were atypical of intracranial CMs and resulted in pathology diagnosing a vascular malformation, not otherwise specificed. ${ }^{26,55}$ Finally, although less likely, it is possible that the lesion represented a mixed vascular malformation-a well-described entity containing elements of more than one angiographically occult type of vascular malformations. ${ }^{4}$

\section{Cranial Nerve Associated AOVMs-Surgical Considerations}

Important surgical considerations and technique differences in the approach and resection of AOVM-most frequently $\mathrm{CM}$-associated with cranial nerves merit discussion, as they differ from their more common intraparenchymal counterparts. In a parenchymal AOVM, the surgical strategy relies on development of a circumferential plane around the lesion and subsequent en bloc removal. In a cranial nerve-associated AOVM, this strategy must be modified to account for the intimate rela- tionship between the lesion and the cranial nerve. The proposed surgical strategy is similar to that used in the resection of nerve sheath tumors, in which there is a focus on early identification of the involved nerve rootlet. In our case at least one rootlet of the spinal component of the spinal accessory nerve entered and exited the central substance of the mass and therefore could not be salvaged. The medullary roots of the spinal accessory nerve, however, were well visualized and were preserved by dissecting the arachnoid away from the capsule of the mass. Postoperatively, the trapezius and sternocleidomastoid muscle strength was intact, likely due to the meticulous identification and sacrifice only of the affected rootlet.

\section{Spinal Accessory Nerve and AOVMs}

To our knowledge, there is one reported case of an AOVM of the spinal accessory nerve in a patient who presented with progressive upper- and lower-extremity paresthesias and pain secondary to spinal cord compression. ${ }^{23}$ The lesion was located extracranially, at the level of the atlas. Histopathology was typical for a CM. Therefore, we report the first case in the literature of an intracranial accessory nerve AOVM located within the cerebellomedullary cistern confirmed by the histopathological documentation of nerve fibers coursing through the lesion. The differential diagnosis of a cerebellomedullary cistern mass should include meningioma, schwannoma, malignant peripheral nerve sheath tumors, ependymoma, andalthough rare-AOVMs. ${ }^{25,35,50,54}$ For CMs located within the cerebellomedullary cistern as well as for any AOVM located within any cistern or suspected to be involving a cranial nerve, we recommend including immunohistochemistry with primary antibody to neurofilament in the histopathology workup.

\section{References}

1. Adachi K, Yoshida K, Akiyama T, Kawase T: Cavernous angioma of the vestibular nerve: case report and literature review. Surg Neurol 70:82-86, 2008

2. Albanese A, Sturiale CL, D'Alessandris QG, Capone G, Maira G: Calcified extra-axial cavernoma involving lower cranial nerves: technical case report. Neurosurgery 64:onsE135-onsE136, 2009

3. Arrué P, Thorn-Kany M, Vally P, Lacroix F, Delisle MB, Lagarrigue $\mathrm{J}$, et al: Cavernous hemangioma of the intracra- 
nial optic pathways: CT and MRI. J Comput Assist Tomogr 23:357-361, 1999

4. Awad IA, Robinson JR, Mohanty S, Estes ML: Mixed vascular malformations of the brain: clinical and pathogenetic considerations. Neurosurgery 33:179-188, 1993

5. Babu R, Ransohoff J, Cohen N, Zagzag D: Cavernous angiomas of the internal auditory canal. A case report and review of literature. Acta Neurochir (Wien) 129:100-104, 1994

6. Bordi L, Pires M, Symon L, Cheesman AD: Cavernous angioma of the cerebello-pontine angle: a case report. Br $\mathbf{J}$ Neurosurg 5:83-86, 1991

7. Bricolo A, De Micheli E, Gambin R, Alessandrini F, Iuzzolino P: Cavernous malformation of the internal auditory canal. A case report. J Neurosurg Sci 39:153-158, 1995

8. Brunori A, Chiappetta F: Cystic extra-axial cavernoma of the cerebellopontine angle. Surg Neurol 46:475-476, 1996

9. Capelle HH, Nakamura M, Lenarz T, Brandis A, Haubitz B, Krauss JK: Cavernous angioma of the geniculate ganglion. J Neurosurg 109:893-896, 2008

10. Cecchi PC, Rizzo P, Faccioli F, Bontempini L, Schwarz A, Bricolo A: Intraneural cavernous malformation of the cauda equina. J Clin Neurosci 14:984-986, 2007

11. Cho WS, Kang HS, Kim JW, Kee Park C, Kim JE: Cavernous malformation of the cisternal trigeminal nerve. Br J Neurosurg 25:339-340, 2011

12. Chow M, Addas B, Sangalang V, Holness R: Cavernous malformation of the hypoglossal nerve: case report and review of the literature. Can J Neurol Sci 29:191-194, 2002

13. Corboy JR, Galetta SL: Familial cavernous angiomas manifesting with an acute chiasmal syndrome. Am J Ophthalmol 108:245-250, 1989

14. Deshmukh VR, Hott JS, Tabrizi P, Nakaji P, Feiz-Erfan I, Spetzler RF: Cavernous malformation of the trigeminal nerve manifesting with trigeminal neuralgia: case report. Neurosurgery 56:E623, 2005

15. Di Rocco F, Paterno V, Safavi-Abbasi S, El-Shawarby A, Samii A, Samii M: Cavernous malformation of the internal auditory canal. Acta Neurochir (Wien) 148:695-697, 2006

16. Escada P, Capucho C, Silva JM, Ruah CB, Vital JP, Penha RS: Cavernous haemangioma of the facial nerve. J Laryngol Otol 111:858-861, 1997

17. Fehlings MG, Tucker WS: Cavernous hemangioma of Meckel's cave. Case report. J Neurosurg 68:645-647, 1988

18. Ferrante L, Acqui M, Trillò G, Antonio M, Nardacci B, Celli P: Cavernous angioma of the VIIIth cranial nerve. A case report. Neurosurg Rev 21:270-276, 1998

19. Ferreira NP, Ferreira MP: Optic nerve apoplexy caused by a cavernous angioma: case report. Neurosurgery 30:262-264, 1992

20. Hankey GJ, Khangure MS: Chiasmal apoplexy due to intrachiasmatic vascular malformation rupture. Aust N Z J Med 17:444-446, 1987

21. Hassler W, Zentner J, Petersen D: Cavernous angioma of the optic nerve. Case report. Surg Neurol 31:444-447, 1989

22. Hassler W, Zentner J, Wilhelm H: Cavernous angiomas of the anterior visual pathways. J Clin Neuroophthalmol 9:160-164, 1989

23. Hazzard MA, Patel NB, Hattab EM, Horn EM: Spinal accessory nerve cavernous malformation. J Clin Neurosci 17:248-250, 2010

24. Hegde AN, Mohan S, Lim CCT: CNS cavernous haemangioma: "popcorn" in the brain and spinal cord. Clin Radiol 67:380-388, 2012

25. Ho TP, Samuel PR, Jeannon JP, McElroy J: Malignant peripheral nerve sheath tumour of the spinal accessory nerve. J Laryngol Otol 113:942-944, 1999

26. Hoya K, Asai A, Sasaki T, Kimura K, Kirino T: Expression of smooth muscle proteins in cavernous and arteriovenous malformations. Acta Neuropathol 102:257-263, 2001
27. Hufnagel TJ, Cobbs WH: [Microangioma and optochiasmatic apoplexy. Description of an anatomo-clinical entity associating spontaneous hemorrhages of the anterior optic pathways and rupture of cryptic vascular anomalies.] J Fr Ophtalmol 11:81-84, 1988 (Fr)

28. Iplikçioğlu AC: Cavernous angioma involving the 7th nerve. Br J Neurosurg 5:651, 1991 (Letter)

29. Iplikçioğlu AC, Benli K, Bertan V, Ruacan S: Cystic cavernous hemangioma of the cerebellopontine angle: case report. Neurosurgery 19:641-642, 1986

30. Itshayek E, Perez-Sanchez X, Cohen JE, Umansky F, Spektor S: Cavernous hemangioma of the third cranial nerve: case report. Neurosurgery 61:E653, 2007

31. Iwai Y, Yamanaka K, Nakajima H, Miyaura T: Cavernous angioma of the optic chiasm--case report. Neurol Med Chir (Tokyo) 39:617-620, 1999

32. Kim M, Rowed DW, Cheung G, Ang LC: Cavernous malformation presenting as an extra-axial cerebellopontine angle mass: case report. Neurosurgery 40:187-190, 1997

33. Kivelev J, Laakso A, Niemelä M, Hernesniemi J: A proposed grading system of brain and spinal cavernomas. Neurosurgery 69:807-814, 2011

34. Klein LH, Fermaglich J, Kattah J, Luessenhop AJ: Cavernous hemangioma of optic chiasm, optic nerves and right optic tract. Case report and review of literature. Virchows Arch A Pathol Anat Histol 383:225-231, 1979

35. Liechty P, Tubbs RS, Loukas M, Blount JP, Wellons JC, Acakpo-Satchivi L, et al: Spinal accessory nerve meningioma in a paediatric patient: case report. Folia Neuropathol 45:23-25, 2007

36. Malik S, Cohen BH, Robinson J, Fried A, Sila CA: Progressive vision loss. A rare manifestation of familial cavernous angiomas. Arch Neurol 49:170-173, 1992

37. Manjila S, Moon K, Weiner MA, Cohen ML, Leigh RJ, Megerian CA, et al: Cavernous malformation of the trochlear nerve: Case report and review of the literature on cranial nerve cavernomas. Neurosurgery 69:E230-E238, 2011

38. Maruoka N, Yamakawa Y, Shimauchi M: Cavernous hemangioma of the optic nerve. Case report. J Neurosurg 69:292294, 1988

39. Mascarenhas L, Magalhães F, Magalhães Z, Romão H, Resende M, Resende-Pereira J, et al: Cavernous malformation of the trigeminal nerve. Neurocirugia (Astur) 17:64-67, 2006

40. Matias-Guiu X, Alejo M, Sole T, Ferrer I, Noboa R, Bartumeus F: Cavernous angiomas of the cranial nerves. Report of two cases. J Neurosurg 73:620-622, 1990

41. Mirzayan MJ, Capelle HH, Stan AC, Goetz F, Krauss JK: Cavernous hemangioma of the cavernous sinus, skin, and retina: hemodynamic changes after treatment: case report. Neurosurgery 60:E952, 2007

42. Miyashita T, Hoshikawa H, Kagawa M, Mori N: A case report of facial nerve hemangioma. Auris Nasus Larynx 34:519-522, 2007

43. Moon KS, Jung S, Lee KH, Lee MC: Cavernous hemangioma of the abducens nerve: clinical implication of duplicated variants: case report. Neurosurgery 69:E756-E760, 2011

44. Muzumdar DP, Bhatjiwale MG, Goel A, Doshi P: Cavernous haemangioma in the interpeduncular cistern: case report and review of literature. J Postgrad Med 47:191-193, 2001

45. Ogilvy CS, Pakzaban P, Lee JM: Oculomotor nerve cavernous angioma in a patient with Roberts syndrome. Surg Neurol 40:39-42, 1993

46. Pappas DG, Schneiderman TS, Brackmann DE, Simpson LC, Chandra-Sekar B, Sofferman RA: Cavernous hemangiomas of the internal auditory canal. Otolaryngol Head Neck Surg 101:27-32, 1989

47. Pereira de Morais NM, Mascarenhas ALR, Soares-Fernandes JP, Moreira da Costa JA: Cranial nerve cavernous 
malformations causing trigeminal neuralgia and chiasmal apoplexy: Report of 2 cases and review of the literature. Surg Neurol Int 3:105, 2012

48. Pham M, Gross BA, Bendok BR, Awad IA, Batjer HH: Radiosurgery for angiographically occult vascular malformations. Neurosurg Focus 26(5):E16, 2009

49. Samii M, Nakamura M, Mirzai S, Vorkapic P, Cervio A: Cavernous angiomas within the internal auditory canal. J Neurosurg 105:581-587, 2006

50. Sheikh OA, Reaves A, Kralick FA, Brooks A, Musial RE, Gasperino J: Malignant nerve sheath tumor of the spinal accessory nerve: a unique presentation of a rare tumor. J Clin Neurol 8:75-78, 2012

51. Sindou M, Gilg A, Vighetto A, Jouvet A: Cryptic angioma in the trochlear nerve. Excision of the invaded portion and successful repair with an autologous graft: case report. Neurosurgery 30:255-258, 1992

52. Steinberg GK, Chang SD, Gewirtz RJ, Lopez JR: Microsurgical resection of brainstem, thalamic, and basal ganglia angiographically occult vascular malformations. Neurosurgery 46:260-271, 2000

53. Sürücü O, Sure U, Mittelbronn M, Meyermann R, Becker R: Cavernoma of the trochlear nerve. Clin Neurol Neurosurg 109:791-793, 2007

54. Tatebayashi K, Tanaka Y, Numata H, Kawakami S, Kamitani $\mathrm{H}$, Watanabe T: Schwannoma of the spinal accessory nerve in the cisterna magna. Surg Neurol 59:217-222, 2003

55. Uranishi R, Baev NI, Kim JH, Awad IA: Vascular smooth muscle cell differentiation in human cerebral vascular malformations. Neurosurgery 49:671-680, 2001

56. Vanefsky M, Cheng M, Chang S, Norbash A, Snipe J, Marks $\mathrm{M}$, et al: Correlation of magnetic resonance characteristics and histopathological type of angiographically occult vascular malformations. Neurosurgery 44:1174-1181, 1999
57. Whitehead KJ, Plummer NW, Adams JA, Marchuk DA, Li DY: CCM1 is required for arterial morphogenesis: implications for the etiology of human cavernous malformations. Development 131:1437-1448, 2004

58. Yamada T, Nishio S, Matsunaga M, Fukui M, Takeshita I: Cavernous haemangioma in the oculomotor nerve. A case report. J Neurol 233:63-64, 1986

59. Zentner J, Grodd W, Hassler W: Cavernous angioma of the optic tract. J Neurol 236:117-119, 1989

\section{Disclosure}

The authors report no conflict of interest concerning the materials or methods used in this study or the findings specified in this paper.

\section{Author Contributions}

Conception and design: Martin, Terterov, McLaughlin. Acquisition of data: all authors. Analysis and interpretation of data: Terterov, McLaughlin, Vinters. Drafting the article: Terterov, McLaughlin. Critically revising the article: all authors. Reviewed submitted version of manuscript: all authors. Approved the final version of the manuscript on behalf of all authors: Martin. Study supervision: Martin. Slide preparation and interpretation: Vinters.

\section{Correspondence}

Neil A. Martin, Department of Neurosurgery, David Geffen School of Medicine at UCLA, Ronald Reagan UCLA Medical Center, 757 Westwood Plaza, Ste. 6236, Los Angeles, CA 90095 7436. email: neilmartin@mednet.ucla.edu. 